\title{
A Operação Município e a Técnica de Descentralização Admenistrativa
}

\section{A. DELORENZO Neto}

$\mathrm{N}$

o mecanismo da Administração Pública - para a solução das ingentes tarefas que lhe são atribuídas no Estado moderno - tem precedência o exame do problema financeiro. Reconhecida essa precedência, na organização estatal, êle se transforma na discussão dos sistemas da discriminação de rendas. A Constituição Federal, adotando um dêles, estabeleceu, em discriminação exigida entre os entes federados, as receitas que lhes cabem. Do ponto de vista administrativo estamos diante de um fato consumado. Qualquer discussão teórica sôbre a oportunidade ou inoportunidade, erros ou desacertos do texto constitucional, redunda, sem dúvida, numa discussão cerebrina. O que importa considerar, isto sim, é nos meios adequados, práticos e seguros, de serem enfrentadas as deficiências da Constituição, em suas repercussões na atividade interna dos três níveis de Govêrno, e mais particularmente, em relação ao mais pobre dêles o município. A União encontra os meios financeiros que the possibilitam a realização de seus objetivos, no Orçamento. Os princípios que devem reger a elaboração orçamentária obedecem ao disposto no art. 73 , em cujo critério normativo pređominam como condições necessárias à sua própria natureza a unidade, a periodicidade anual e a especialidade dos créditos. Adotado o princípio da universalidade, o orçamento federal há de abranger tôdas as receitas e tôdas as despesas; e quanto ao custeio dos serviços públicos, obedecida a exigência da discriminação, é preciso que se incluam separada e não englobadamente. Além do disposto no art. 73, há regras especiais sôbre a aplicação anual da receita para certos casos relevantes, tais como o desenvolvimento do Ensino, o Plano de defesa contra os efeitos da sêca do Nordeste e o plano de valorização econômica ou Amazônia, consubstanciadas nos artigos 169, 198 e 199. Evidentemente a Seção VI, do Capítulo VI da Constituição Federal, versando sôbre o Orçamentơ não estabelece nenhuma norma especial sôbre aplicação de dotações aos Municípios, a exemplo dos artigos citados, mas também não ocorre ali (como em todo o seu sexto) nenhuma cláusula negatória ou restritiva dessa aplicação. Por outro lado, poder-se-ia considerar como impróprio à Constituição conceder tratamento particular aos municípios ao tratar da matéria orçamentária da União, tendo em vista a discriminação rígida de rendas adotada em corres- 
pondência e entidades intraestatais rígidas. Nestas condições, o raciocínio nos condiziria a conceber uma economia própria para os problemas próprios, dentro dos orçamentos, na conformidade de sua natureza federal, estadual ou municipal. Se a discriminação de rendas estabelecida no art. 29 é de boa técnica, porque nos permite saber quais os impostos e taxas que são municipais "por natureza", e quais os impostos e taxas além dêsses, isto é, "por preceito da Constituição de cada Estado - membro", por outro lado ela limita o desenvolvimento das finanças locais, que assim concebido em têrmos rígidos constitui um entrave ao progresso dos municípios, máxime em país como o nosso abatido por desajustamentos e crises freqüentes. Nos países que adotam o sistema flexível em matéria financeira, tôda assistência aos entes locais é facilitada pelo simples mecanismo das leis ordinárias. Portanto, a alegação de que os municípios desnecessitam de uma ajuda sistemática através do Orçamento da União, porque possuem para economia própria fortemente alicerçada na Constituição em face da discriminação de rendas do art. 29 não procede. Essa ajuda financeira, considerados os defeitos da discriminação constitucional, é tanto mais legítima e imprescindível, se atentarmos à penosa situação deficitária em que se encontram os municípios brasileiros. E' o de que nos convencem êstes elementos sucintos e expressivos:

SITUAÇÃO GERAL DAS FINANÇAS MUNICIPAIS - DADOS DO I.B.G.E.

Receita Global dos Municipios Cr\$ $1.000,00$

\begin{tabular}{c|c|c}
\hline 1948 & 1949 & 1950 \\
\hline 2.821 .655 & 3.753 .915 & 4.794 .286 \\
\hline
\end{tabular}

DEFICIT

\begin{tabular}{l|l|l}
\hline-77.405 & $-299.78-$ & -401473 \\
\hline
\end{tabular}

Nem se dirá que o deficit seja motivado pela prática de empréstimos para obras produtivas: essas operações são muito escassas, tendo sido estimuladas muito recentemente, e mesmo assim nos grandes Estados, como o de São Paulo. O quadro acima denuncia, pois, a situação da crise municipal oriunda, sem dúvida, em grande parte da escassez de recursos financeiros. Torna-se imperioso seja a tendência municipalista da Constituição efetivada por medidas complementares que, sem enfrentar os percalços de uma alteração do seu texto, inoportuna e demorada, possibilitem imediato fortalecimento do poder financeiro das Prefeituras. E, dentro do espírito da Constituição - que deve ser interpretada num sentido político - social, para dar ao Govêrno todos os instrumentos possíveis que permitam a ascenção das coletividades territorialmente diferenciadas ao bem comum - é que se pode utilizar o Orçamento Federal como um meio de emergência para o atendimento de 
tantas reivindicações municipais. Aliás, acolhida a participação direta da União, através da sua lei de Meios - ou de Orçamentos especiais, como o do plano Salte, — na recuperação municipal, ter-se-á adotado uma prática que concorda com a tendência moderna de ampliarem-se os seus quadros clássicos. A propósito Laufenburger, o insigne professor de Finanças na Faculdade de Direito de Paris, declara que: "Les finances publiques ont perdu leur caracteré de neutralité, elles ont eté mises partout au service de la politique economique et sociale". (1) Perdendo a sua "neutralidade" os Orçamentos da União, assistindo aos Municípios, ganhará um sentido de base, passando a constituir uma poderosa via técnicamente acessível à atribuição de ajuda financeira aos empreendimentos de que tanto carecem.

\section{II}

A Operação-Município, ou seja, o Plano Nacional de Obras e Serviços Municípios - objeto de Recomendação Especial aprovada pelo II Congresso Nacional de Municípios, em São Lourenço - fundada nessas possibilidades constitucionais e técnicas, vem resolver definitivamente o problema assistencial para as áreas locais. A amplitude dos seus objetivos vem claramente enunciada no art. $2 .^{\circ}$ do projeto Jarbas Maranhão, pelo qual foi levado a debate na Câmara dos Deputados, e que dispõe:

"O Plano Nacional de Obras e Serviços Municipais (Operação-Município) terá como objetivo principal promover o desenvolvimento econômico social dos municípios brasileiros, de maneira que os transforme em unidades de sustentação dơ progresso econômico-social do país, especialmente em seus aspectos agrícola - industrial, preservação da saúde pública, difusão do ensino técnico profissional aparelhamento para os transportes e comunicações e produção de energia".

Convém ainda referir o $\S 10^{\circ}$ do artigo citado:

"Art. 1. 0 objetivo visado no artigo deverá ser alcançado mediante: I - a criação da Comissão Nacional Organizadora do Plano;

II - a votação, em lei especial, do Fundo Financeiro, constituído de recursos vinculados às obras, serviços e demais empreendimentos a serem computados no Plano;

III - a criação da Comissão Nacional Executiva do Plano, cuja organização deverá ser pautada nos moldes da administração do Plano Salte;

IV - a assinatura de convênios nos quais fique estabelecida, tanto quanto possível, a descentralização administrativa mitigada, reservando-se à União a orientação e o contrôle técnico dos respectivos projetos, de modo que se ressalve a aplicação dos recursos na forma prevista pela presente lei e atos que the forem subseqüentes ou complementares;

(1) Finances Comparées, Paris, p. 325. 
V - a votação de lei especial relativa ao sistema financeiro da execução do Plano, atendidos os fundamentos que presidem o da execução do Plano Salte;

VI - a formulação do projeto do Plano (Lei de Programa) pela Comissão Nacional Organizadora do mesmo, a fim de que seja encaminhada ao Congresso para votação de lei especial integrada pelas tabelas discriminativas das obras, serviços e demais empreendimentos a serem atendidos".

O Plano será executado em cinco exercícios e abrangerá o total de Cr\$ 15.000.000.000,00 (quinze bilhões de cruzeiros) na sua primeira fase, porém, o projeto em seu artigo 11 cogita da abertura do crédito especial de Cr\$ $5.000 .000,00$ (cinco milhỡes de cruzeiros) para os trabalhos da sua comissão Nacional Organizadora .

Pois bem, de acôrdo com o exposto, a Operação Município adotará a metodologia do Plano Salte, estruturando-se em Orçamento especial. E, nestas condições, se transformará em técnica de descentralização administrativa, das mais poderosas e eficazes que temos conhecido, porquanto exercerá uma ação transformadora na vida municipal pela multiplicação dos investimentos, criação de utilidades e disseminação através do vasto hinterland de tơdos os instrumentos de civilização necessárias à valorização e ascenção das massas rurais. A Operação-Município representará, por isso mesmo, um elemento de estímulo e robustecimento à autonomia política. Sem firmes fases financeiras, esta se tornará precária e inexistente, ou mera ficção jurídica a serviço da demagogia e da aventura política. Não será a Operação-Município um modo pelo qual passará a União a controlar maquiavèlicamente os municípios: será, ao contrário, a fórmula legal mais adequada de cooperação financeira, no seio da qual, em sua plenitude, se assegura uma comunicação de recursos dentro da mais apurada técnica das relações interadministrativas, que tão grande relêvo vem adquirindo no direitơ público contemporâneo. Neste particular, convém lembrar a lição do eminente jurista uruguaio APARício MEN$\mathrm{DEZ}$, que ensina: "Al fragmentar-se el Estado en entidades con poderes propios de origem constitucional o legal se produce automaticamente um conjunto de negociaciones o vinculaciones de carácter subjetivo y transitorio, por medio de los cuales se trata voluntariamente de obtener prestaciones recíprocas, de exigir el cumplimiento de servicios estabelecidos por la ley, de pac$\operatorname{tar}$ la ejecucion de obligaciones pendientes. Se trata, pues, tal como se presenta loy e la consideracion del estudioso, de um problema típico de los regimenes com amplia descentralizacion. La specializacion funcional hace que cada ente descentralizado tenga que recurrir o al poder central e a los órganos departamentales e a los organismos similares para obtener la prestacion de determinados servicios".

Nos Estados federais as relações interadministrativas melhor se objetivam, nos interêsses superiores das populações, pela prática da descentralização. $\mathrm{E}$ a descentralização administrativa é o processo que nos demonstra cla-

(2) Las Relaciones Inter-administrativas, Montevidéo, 1943, p. 12. 
ramente, que, em verdade o poder federal é uma sintese de poderes locais, e que não existindo por si é a expressão dessas unidades autônomas. O Estado Federal enquanto sistema, como todo racionalmente organizado, só existe em função dos elementos, que o compõe. O reconhecimento das influências locais sôbre os assuntos gerais, determinando uma nítida correlação entre descentralização política e a descentralização administrativa pode ser observada nos Estados Unidos. Portanto, a teoria e a prática nos encaminham a considerar indispensável ao progresso da Nação, a cooperação cada vez mais estreitada entre a União e os poderes locais, e cada vez mais reduzida a possibilidade de conflito entre êles.

A Operação-Município vem operar o reerguimentơ dos municípios brasileiros, sobretudo, tendo em vista a sua função descentralizadora. Essa a nosso ver a sua característica fundamental, essencial. E como técnica de descentralizaçâo político-administrativo, que irá contribuir para o melhor conhecimento das áreas locais, sua expansão e limites funcionais. (3) As dimensões com que foi elaborada, o seu sentido moderno de técnica descentralizadora a serviço da administração, a sua aptidão para restaurar valores econômicos nas áreas empobrecidas - fazem com que deva merecer todo apoio dos nossos legisladores, a fim de que transformada em lei venha, ainda em tempo sanear tantos males que afligem as populações rurais e urbanas do Brasil.

(3) ef. Temistocles BRandão Cavalcanti - Quatro Estudos - Rio, 1954, p. 29. Conforme esclarece êste ilustre mestre, são notáveis os estudos sôbre as áreas locais, do professor Lipman, da Universidade de Oxford.

Com um atraso de mais de meio século, no tratamento do problema em relação aos Estados Unidos da América, a administração federal do Brasil está cogitando de implantar um sistema de classificação (de cargos) ao mesmo tempo que procura atender às necessidades econômicas prementes do funcionalismo civil.

Arízio de Viana, DASP, Instituição a Serviço do Brasil, 1953. 